As to the gynæcological history, the patient was married in the Brahminical sense in her tenth year, which is equivalent to a betrothal, but the consummation took place after she attained the age of maturity in her fourteenth year. She gave birth to six sons and two daughters, of whom two sons and two daughters have died in their infancy. About $1 \frac{1}{1}$ years before her admission she gave birth to her last child, who was alive for four months. Menstruation appeared five months after her last confinement and continued for five days. It continued regularly for three months. Since then she has had sero-sanguineous discharge from the vagina once in 15 or 20 days without any pain, the discharge continuing for three or four days. About three months prior to her admission she passed clots of blood without pain, for which she was treated for eight days. About 15 days prior to her admission she had another attack of hæmorrhage which lasted for a day only. Coitus had taken place off and on since the death of her last child, and she used to pass blood in small quantities on each occasion.

The patient on admission was ill-nourished. She had lost flesh and colour since the commencement of the hæmorrhage. Her appetite was good. No temperature. Heart and pulse were normal. On vaginal examination the cervix was found ulcerated and excavated. The edges of the ulcer were hard and indurated. The ulcerated area was friable and bled easily. The discharge was very offensive and purulent. The vaginal wall was not involved. On bimanual examination the body of the uterus was felt enlarged and freely movable. The sacro-uterine ligaments were felt to be free on rectal examination. The cervix could be brought down easily with the aid of a vulsellum forceps.

An operation was performed on April 29th, 1912. The ulcerated area was cauterised and the whole uterus removed by vaginal hysterectomy. The anterior and posterior vaginal walls were left ununited, and a gauze drain was passed into the pelvic cavity. The patient made a good recovery and was discharged from the hospital on June 8th.

On cutting open the uterus (see figure) there were seen, to my surprise, twins, each foetus being enclosed in a separate amnion. The idea of pregnancy never entered my mind on account of the frequent hæmorrkages. The age of the fotuses was probably 3 months.

Bangalore.

\section{A CASE OF}

\section{RHEUMATIC ARTHRITIS TREATED WITH} RHEUMATISM PHYLACOGEN.

\section{BY MARIAN ERSKINE, L.R.C.P. \& S. EDIN., L.F.P.S. GLASG.,}

VISITING PHYSICIAN, HOSPITAI FOR WOMEN AND CHILDREN,

$$
\text { EDINBURGH. }
$$

IN view of the comparatively recent introduction of the phylacogens into therapeutics the following case may present some points of interest.

The patient, 33 years of age, was admitted into the Edinburgh Hospital for Women and Children on May 2nd, 1913 , complaining of pain, stiffiness, and swelling of the left knee and hip so severe as to render walking impossible. The condition started during the autumn of 1912 with an acute attack of pain and swelling of the left knee, and subsequently the left hip became involved.

On admission the left knee was found to be greatly swollen and very painful and tender to the touch. Any attempt at active or passive movement gave rise to the most intense pain. The left hip was affected in a similar manner, but in a less degree. Apart from the local condition, the patient's general health was fairly good and she was well nourished. There was a considerable degree of constipation, but there was no evidence of bacterial infection. The constipation was treated, diet was regulated, and the usual remedies were given, including radiant heat and ionisation with potassium iodide, but at the end of a month's treatment there was no noticeable improvement in the symptoms. Accordingly, I resolved to try the effect of rheumatism phylacogen, having heard reports of the good effects of this preparation in similar cases. On May 29th I began with a subcutaneous injection of 2 c.c. About 12 hours after the injection the patient had a slight reaction, the temperature and pulse rose, and she felt sick and vomited a little. Thereafter the injection was repeated every second day, increasing the dose each day till eventually she was receiving 10 c.c. The reaction after each dose was fairly severe, the temperature rising to from $100^{\circ}$ to $102^{\circ} \mathrm{F}$., the pulse increasing to 115 , and the patient complaining of pain in all her joints. These symptoms quickly subsided, however, and after the third injection the knee was distinctly less swollen and tender, and was slightly movable. This improvement steadily continued, the pain in the hip and knee gradually subsided, and on June 8th, after the sixth injection, the patient could flex and extend her leg without pain, and the swelling had practically gone. On the 14th she was allowed up for the first time, and found that she could walk about the ward without much difficulty. On the 22nd she was discharged-walking out of hospital.

Before admission the patient had not been able to walk for three months. On July 14th she reported herself as having had no return of pain, swelling, or difficulty in walking, and as being quite able to undertake her daily work.

The time that has elapsed since the cessation of the treatment is of course too short to preclude the return of the symptoms, but the results, in view of the failure of other remedies, seem sufficiently encouraging to warrant the further trial of this preparation.

Apparently also the remedy is of benefit in obstinate cases of myalgia and neuralgia. This was evident in a case of sciatica in a young woman. When this patient came under my care she had been suffering from an attack of three or four weeks' duration, the pain being sufficiently severe to keep her awake at nights and to render movement a matter of difficulty. There was tenderness at all the nodal points of the left sciatic nerve and some fibrosis of the muscles of the left thigh and leg. Ordinary remedies had failed to produce any amelioration of the symptoms. The first two doses (2 c.c. and 3 c.c.) gave rise to no reaction, and had little, if any, effect on the pain; but the third injection (5 c.c.) was followed by a sharp rise of temperature and pulse, accompanied by intense pain and swelling of the left arm and shoulder, which persisted for a couple of days. The sciatic pain, however, had completely gone, and this fact, combined with the discomfort of the reaction, made the patient refuse further injections. She remained under my observation for three weeks longer, during which time she had no return of the pain, and was able to walk and run without any difficulty at all. Another case of obstinate lumbago in a woman of 48 was followed by a similarly satisfactory result. Edinburgh.

FOREIGN UNIVERSTTY INTELLIGENCE.Genoa: Dr. Piero Boggio has been recognised as privatdocent of Odontology.-Georgia, University of (Augusta College of Medicine): Dr. R. Vanderhorst Lamar has been appointed Professor of Pathological Anatomy.Helsingfors: Dr. A. Erlandsen, of Copenhagen, has been appointed to the chair of Hygiene, in succession to the late Dr. Hjelt.-Jena: Dr. R. Eden has been recognised as privat-docent of Surgery.-Leyden: Dr. E. de Vries has been recognised as privat-docent of Neurology._Modena: Dr. Virginio Ramazotti has been recognised as privat-docent of Dermatology and Syphiligraphy.-Montreal (MoGill University): Dr. Campbell Geddes, professor of anatomy at the Royal College of Surgeons in Ireland, has been appointed to the chair of Anatomy.-Munich: Dr. L. von Zambusch, of Vienna, has been appointed Extraordinary Professor of Dermatology.-Palermo: Dr. Vincenzo Baviera has been recognised as privat-docent of External Pathology. - Pavia: Dr. Ernesto Brugnatelli has been recognised as privat-docrnt of General Pathology, and Dr. Ambrogio Gradi as privat-docent of Medicine and Medical Semeiology.Philadelphia (Jefferson Medical College): Dr. John C. Da Costa and Dr. F. J. Kalteyer have been appointed Adjunct Professors of Medicine--San Franoiseo (Leland Stanford University): Dr. Thomas Addis has been appointed Adjunct Professor of Medicine.-Stockholm : Dr. J. Holmgren, privat-docent, has been promoted to the Chief Physiciancy of the Medical Clinic, in succession to Dr. Henschen, who is retiring.-Washington (University of St. Louis): Dr. G. Canby Robinson has been appointed Adjunct Professor of Medicine. 